\title{
Optimisation of photoluminescent painting treatments on different surface layers
}

\author{
F.G. Praticò, S. Noto \& A. Moro \\ University Mediterranea of Reggio Calabria, Italy
}

\begin{abstract}
Improving drivers visibility in night time conditions is vital. Night-time visibility represents one of the most important features of road safety. Within such context, the use of photoluminescent road markings could represent an enhancement with regard to road safety. Consequently, the objective of the investigation here described was confined into the analysis of photoluminescent paints by referring to dense-graded and open-graded friction courses. Measurements, based on photometry technique, were carried out in the laboratory. Cores extracted from the surface layer of known pavements were used. Transitory effects (charge and discharge) and decay phenomena were investigated and modelled as a function of treatment and pavement characteristics (paint quantity, hot mix asphalt volumetrics, etc.). The results highlight that the photoluminescent performance depends on the volumetric characteristics of bituminous mixtures. Results can benefit both researchers and practitioners and can allow optimising painting treatments for different bituminous mixtures.
\end{abstract}

\section{INTRODUCTION}

Improving drivers visibility conditions is vital (Bosurgi et al, 2015). Road pavement markings are crucial when concerning night-time visibility. In fact, they provide guidance and safety for drivers. Their most important property is the luminance since it allows improving the view of any device or object during the night.

Luminance is the intensity of brightness and is measured in candela per unit area of a surface $\left(\mathrm{cd} / \mathrm{m}^{2}\right)$. The basics which allows estimating photoluminescent effects are below explained (see also Table. 1)

The luminance is defined by the derivative:

$$
L_{V}=\frac{d^{2} \Phi_{V}}{d A d \Omega \cos \theta}
$$

where $\mathrm{L}_{\mathrm{V}}$ is the luminance $\left(\mathrm{cd} / \mathrm{m}^{2}\right), \Phi_{\mathrm{V}}$ is the luminous flux or luminous power $(\mathrm{lm}), \theta$ is the angle between the surface normal and the specified direction, $\mathrm{A}$ is the area of the surface $\left(\mathrm{m}^{2}\right)$, and $\Omega$ is the solid angle $(\mathrm{sr})$.

The luminous flux is defined as follows:

$$
\Phi_{V}=V \times W
$$

where $\mathrm{V}$ is the human eye spectral sensitivity ( $\mathrm{lm} / \mathrm{Watt})$ and $\mathrm{W}$ is the luminous power (Watt).

The illuminance is the total luminous flux incident on a surface, per unit area:

$$
E=\frac{d \Phi}{d S}
$$

where $\Phi_{\mathrm{V}}$ is the luminous flux $(\mathrm{lm})$ and $\mathrm{S}$ is the surface $\left(\mathrm{m}^{2}\right)$. 
When visual performance analyses are carried out, the luminance contrast (C) can be considered, as in (Bullough et al, 2014). C is defined by the formula:

$$
C=\left|L_{t}-L_{b}\right| / \max \left(L_{b}, L_{t}\right)
$$

where $\mathrm{Lt}$ is the luminance (in $\mathrm{cd} / \mathrm{m}^{2}$ ) of the target or object to be seen and $\mathrm{Lb}$ (in $\mathrm{cd} / \mathrm{m}^{2}$ ) is the luminance of the target's or object's background.

Overall, the luminance (L) of an object can be estimated by the illuminance (E) on an object and its reflectance ( $\rho$ : 0 is perfectly black; 1 : perfectly white) using the following formula:

$$
L=E \rho / \pi
$$

where $\mathrm{L}$ is in $\mathrm{cd} / \mathrm{m}^{2}$ and $\mathrm{E}$ is in $1 \mathrm{x}$.

In the study carried out by (Bullough et al, 2014), the low contrast value used was 0.2 , and the high contrast value was 0.8 . The range of light levels used in their analyses were from $3 \mathrm{~lx}$, considered a minimum level for night-time visibility in many traffic safety applications (Andre and Owens, 2001), to 300 lx, a level commonly experienced in many interior lighting applications (IES, 2000).

Note that a method to assess visibility (relative visual performance, RVP) was set up by (Rea and Ouellette, 1991). It provides a determination of the speed and accuracy of visual processing (IES, 2000) as a function of: i) Background luminance; ii) Luminance contrast; iii) Target size; iv) Observer age.

\begin{tabular}{|c|c|c|}
\hline$\left(\mathrm{cd} / \mathrm{m}^{2}\right)$ & $\begin{array}{l}\text { Luminance (L), the intensity of brightness and is measured in candela } \\
\text { per unit area of a surface }\end{array}$ & $\begin{array}{l}\text { See equation } 1 \\
\text { and } 5\end{array}$ \\
\hline & luminous power, measured in lumen, $1 \mathrm{~m}$ & See equation 2 \\
\hline (lx) & $\begin{array}{l}\text { Illuminance }(E) \text {, the measure of how much luminous flux is spread over } \\
\text { a given area, or luminous power incident on a surface. It is measured in lx. }\end{array}$ & $\begin{array}{l}\text { See equations } 3 \\
\text { and } 5\end{array}$ \\
\hline & Luminance contrast (dimensionless) & See equation 4 \\
\hline
\end{tabular}

Table 1. Basics for estimating the effect of phosphorescent paints.

Symbols. C: luminance contrast; 1m: lumen; cd: candela; sr: steradian or square radian (SI unit of solid angle; a full sphere has a solid angle of $4 \pi$ steradians); m: meter; lx: lux.

Note. $1 \mathrm{~lm}=1 \mathrm{~cd} \cdot \mathrm{sr} ; 1 \mathrm{~lx}=1 \mathrm{~lm} / \mathrm{m}^{2}=1 \mathrm{~cd} \cdot \mathrm{sr} / \mathrm{m}^{2}$.

Table 2. International literature about photo-luminescent paints applications to road pavements.

References Type of application

Turnpenny and Crawford, 2014

Road marking made with glow-in-the-dark paint (with strontium aluminate pigments).

Bacero et al., 2014

Luminescent paint with strontium aluminate on Rural and

Bullough et al., 2014 Unilluminated Roads.

Photoluminescent materials for signage, marking and delineation applications in work zones. In particular, tested materials were: yellow photoluminescent paint ( 8 " square), green photoluminescent tape (1" width), red photoluminescent tape (2" width), orange photoluminescent tape (2" width), yellow photoluminescent tape (2" width).

NYC, 2007

Botterman and Smet, 2015 Photoluminescent green safety paint system for line markings. Use of persistent phosphors (a specific type of luminescent materials) for glow-in-the-dark road marks and in combination with solar cells and photo catalytic processes.

Giuliani and Autelitano, $2014 \quad$ Use of afterglow photoluminescent pigments for road wearing courses.

Mishra et al., 2009

Strontium aluminate/polymer composite samples were attached to the surface of asphalt slabs. 
Many materials can be used for marking road pavements, such as paint, tape and spray. Table 2 summarises the international literature on this topic.

In this study the material taken into account is paint. Paints may consist of several typologies (Jiang, 2008): waterborne, conventional solvent, thermoplastic and epoxy paints. The use of these materials is essentially based on their characteristics, like durability and cost. Basically, they differ in the number of components and in the VOC (Volatile Organic Compound, see Paints Directive 2004/42/EC; Jiang, 2008; Bahar et al., 2006; Gates et al., 2003; Migletz et al., 2002; Andrady, 1997). Their performance is often related to the amount of pigments in the resin (Barletta et al., 2014).

In this study an epoxy paint was used. Epoxy is a two-component material. The first component consists of resin, pigment, extenders, and fillers, while the second component acts as a catalyst to accelerate setting time. Epoxy paint has many advantages such as exceptional adhesion to both asphalt and concrete pavements when the pavement surface is properly cleaned before application (Gates et al., 2003). Such property strongly influences the durability, which is very high. Among the advantages there is the low VOC content, even if the chemicals used in the production are classified as hazardous materials. Table 2 focuses on the international literature about photo-luminescent paints applications to road pavements.

\section{OBJECTIVES}

The main object of this study is to assess the effect of photoluminescent treatments on surface luminance of asphalt concretes. In more detail: i) a phosphorescent paint was used; ii) both densegraded and open-graded friction courses were considered. Additionally, effects in terms of charge and discharge time were assessed and related to the volumetric properties of the samples.

\section{PROCEDURES AND STANDARDS}

The study was carried out following the scheme shown in Figure 1. Figure 1 and Tables 3 to 5 summarise laboratory investigations.

The investigation was organized into six main tasks:

Task1. Design of experiments (DOE);

Task2. Material selection and coring (MS);

Task3. Volumetric and surface characteristics before painting: experimental survey on effective porosity and skid resistance;

Task4. Painting. Paints were applied on the surface according to the procedure explained below;

Task5. Luminance measurements. Measurements were carried out in sunny conditions and dark ones;

Task6. Volumetric and surface characteristics after painting. An experimental survey on effective porosity and skid resistance was carried out.

Task7. Data analysis.

In the pursuit of carrying out the research, two typologies of wearing course were considered: Open Graded Friction Courses (OGFC) and Dense Graded Friction Courses (DGFC). Ten cores per type were used. Their gradations are reported in Figure 1.

Cores were investigated in terms of surface properties and volumetric ones. Then they were subjected to the painting treatment.

The laboratory investigation consisted of two main parts: painting activity and volumetric properties survey before and after paint treatment.

Volumetric properties are worth to be investigated because of the paint influence on the global behaviour of the surface (i.e., permeability, acoustic absorption, etc.).

Symbols. DOE: Design of experiments; MS: Material selection and coring; OGFC: Open Graded Friction Course; DGFC: Dense Graded Friction Course; P\%: percentage passing (aggregate gradation); d: sieve opening [mm]. 
The painting treatment consisted of two phases: White Paint (WP) application and Phosphorescent Paint (PP) application. Table 3 illustrates timing and quantities of this process.

Symbols. WP: White Paint; PP: Phosphorescent Paint; Timing: gap between each laying phase.

The surveys were carried out by measuring luminance regularly (with a time interval of 60 minutes during the day).

More specifically, each survey was structured in terms of a sequence of charge and discharge time simulating the real behaviour on site (day-to-night cycle).

Charge time started every day at 9 o'clock, lasting 7 hours.

Afterwards, the discharge time, during the decay of luminance, was observed and measured.

Luminance measurements were carried out for 3 months. Attention was focused on the relationship existing among luminance, volumetric properties, and paint quantity. Luminance measurements were carried out by means of a photometer, specifically a HAGNER Universal Photometer/Radiometer model S4. It is able to measure luminance $\left(0.01-199,900 \mathrm{~cd} / \mathrm{m}^{2}\right.$, in 5 ranges) and illuminance (0.01-199,900 lux, in 5 ranges). The lowest detectable value is $0.01 \mathrm{~cd} / \mathrm{m}^{2}$ or lux ( $+/-1$ digit). Accuracy is better than $\pm 3 \%$ for all common light sources and in daylight.

Tables 4 and 5 summarize the experimental plan and the properties of the samples investigated, before (task 3 ) and after (Table 6) the treatment.

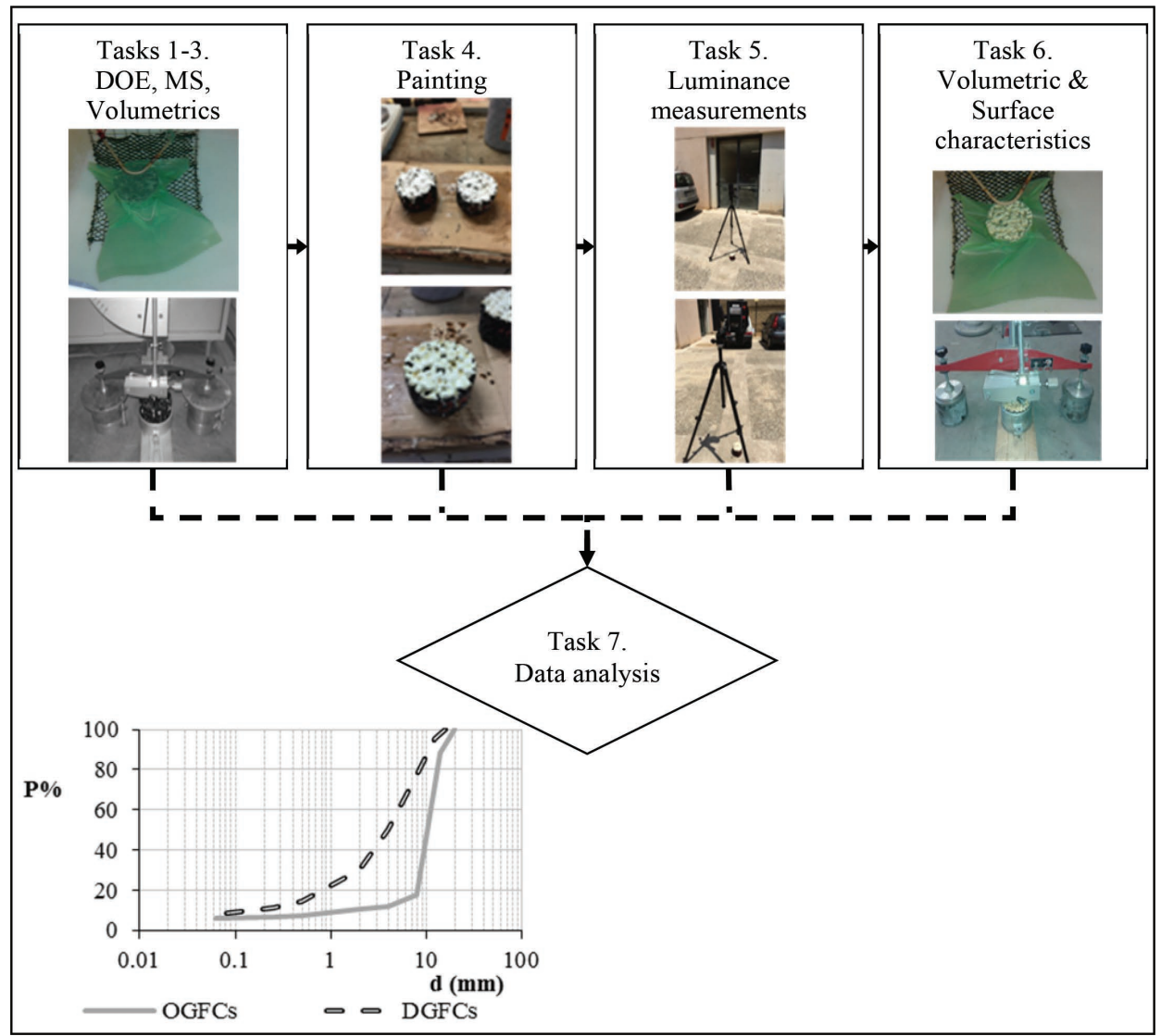

Figure 1. Study's scheme. 
Table 3. Timing and quantities of painting process.

\begin{tabular}{lll}
\hline & Quantity & Timing \\
\cline { 2 - 3 } Paint & [gr] & [minutes] \\
\hline WP & $17 \pm 6$ & $60 \pm 5$ \\
PP & $14 \pm 6$ & $30 \pm 5$ \\
\hline
\end{tabular}

Table 4. Summary of the tests on Cores (C).

\begin{tabular}{llllll}
\hline Sample & $\mathrm{C}_{\mathrm{i}, \mathrm{j}}$ & & & & \\
\hline Test/Process & $\mathrm{G}_{\mathrm{mb}}$ & $\mathrm{n}_{\text {eff }}$ & PTV & $\mathrm{P}$ & $\mathrm{L}$ \\
Ref.* & 1 & 2 & 3 & 4 & 5
\end{tabular}

Symbols. $\mathrm{C}_{\mathrm{i}}$ : Cores; $\mathrm{G}_{\mathrm{mb}}$ : Mix bulk Specific Gravity; $\mathrm{n}_{\text {eff }}$ : Effective porosity; PTV: Pendulum Test Value; P:

Painting; L: Luminance; *: tests defined in Table 5.

Table 5. Summary of tests and standards.

\begin{tabular}{lllll}
\hline Ref. & Parameter & Unit & Test/Process & Standard \\
\hline 1 & $\mathrm{G}_{\mathrm{mb}}$ & - & Mix bulk specific gravity & AASHTO TP 69 (AASHTO 2007) \\
2 & $\mathrm{n}_{\text {eff }}$ & $\%$ & Effective porosity & ASTM D 6752-03 \\
3 & PTV & - & Skid resistance & UNI EN 13036-4:2005 \\
4 & $\mathrm{P}$ & - & Painting & According to the specification sheet \\
5 & $\mathrm{~L}$ & $\mathrm{~cd} / \mathrm{m}^{2}$ & Luminance & DIN 67510 \\
\hline
\end{tabular}

Symbols. $\mathrm{G}_{\mathrm{mb}}$ : Mix bulk Specific Gravity; $\mathrm{n}_{\mathrm{eff}}$ : Effective porosity; PTV: Pendulum Test Value; P: Painting; L: Luminance.

Table 6. Model indicators regarding the OGFCs (left) and the DGFCs (right) based on experiments (I-VIII cycles).

\begin{tabular}{lllllllrrl}
\hline Cycle & $\mathrm{t}_{1}$ & $\mathrm{t}_{2}$ & $\mathrm{t}_{\mathrm{L}}=\mathrm{t}_{2}-\mathrm{t}_{1}$ & $\mathrm{~L}_{\mathrm{M}}$ & Cycle & \multicolumn{1}{c}{$\mathrm{t}_{1}$} & \multicolumn{1}{c}{$\mathrm{t}_{2}$} & $\mathrm{t}_{\mathrm{L}}=\mathrm{t}_{2}-\mathrm{t}_{1}$ & $\mathrm{~L}_{\mathrm{M}}$ \\
\hline I & 484 & 5143 & 4659 & 0.016 & I & 687 & 9631 & 8945 & 0.044 \\
II & 233 & 3857 & 3624 & 0.017 & II & 814 & 18096 & 17282 & 0.037 \\
III & 236 & 3568 & 3332 & 0.020 & III & 939 & 12210 & 11272 & 0.042 \\
IV & 238 & 3614 & 3376 & 0.022 & IV & 904 & 8983 & 8079 & 0.051 \\
V & 248 & 3857 & 3610 & 0.023 & V & 631 & 5667 & 5036 & 0.045 \\
VI & 225 & 3624 & 3399 & 0.014 & VI & 580 & 5251 & 4670 & 0.040 \\
VII & 222 & 3567 & 3345 & 0.019 & VII & 601 & 5702 & 5101 & 0.049 \\
VIII & 213 & 3719 & 3506 & 0.029 & VIII & 956 & 9357 & 8401 & 0.070
\end{tabular}

Symbols. $\mathrm{t}_{1}: \mathrm{t}_{2}[\mathrm{~s}] ; \mathrm{t}_{\mathrm{L}}$ : Luminance time; $\mathrm{L}_{\mathrm{M}}$ : Average luminance.

\section{RESULTS AND ANALYSES}

Figures 2 to 10 and Tables 6 and 7 summarize results and analyses.

\subsection{Main controlled parameters}

The following main parameters were investigated and/or controlled:

- Type of hot mix asphalt (open-graded, OGFC or dense-graded, DGFC);

- Quantity of white paint (WP); 
- Quantity of phosphorescent paint (PP);

- Solar radiation $\left(\mathrm{W} / \mathrm{m}^{2}\right)$;

- cycle of charge-discharge: Charge Time, CT; Discharge Time, DT; luminance time, $\mathrm{t}_{\mathrm{L}}$.

Solar radiation and temperatures were measured by means of a specific device (Vaisala HydroMet ${ }^{\mathrm{TM}}$ Automatic Weather Station MAWS201). It is a portable AWS (Automatic Weather Station) for temporary installations. The MAWS201 is field-proven in a wide range of applications, among them the solar radiation. It consists of 5 basic sensors, a solar panel and a battery.

By referring to the solar radiation it is noted that, based on latitude, day of the year, under conditions of absence of clouds, the solar radiation should measure about $1 \mathrm{~kW} / \mathrm{m}^{2}$ (instead of 0.9 as per Figure 2). Indeed, solar radiation represents the amount of power that would be received by a tracking concentrator in the absence of cloud, based on local solar time, latitude $\left(38^{\circ} 06^{\prime} 37^{\prime \prime} \mathrm{N}\right)$, and the day of the year.

Figure 2 illustrates how the solar radiation (measured through the above mentioned device) varies over time. Note that experimental data fit with the theoretical solar radiation as per predictive equations (which are based on the equation of the sun's position in the sky throughout the year).

Figures 2-5 illustrate the variation over time of:

- Solar radiation $\mathrm{SR},\left(\mathrm{W} / \mathrm{m}^{2}\right)$, predicted and observed;

- Air temperature T, $\left({ }^{\circ} \mathrm{C}\right)$

- Daytime luminance $\mathrm{L}_{\mathrm{d}}$, (hcd $/ \mathrm{m}^{2}$, where hcd $\left.=10^{2} \mathrm{~cd}\right)$;

- Night-time Luminance $\mathrm{L}_{\mathrm{n}},\left(\mathrm{mcd} / \mathrm{m}^{2}\right.$, where $\left.\mathrm{mcd}=10^{-3} \mathrm{~cd}\right)$.

Note that:

i. the solar radiation has a peak of $0.9 \mathrm{~kW} / \mathrm{m}^{2}$ at about $12 \mathrm{am}$;

ii. there is a lag of about two hours between SR and T peaks;

iii. the daytime luminance has a peak of $322 \mathrm{hcd} / \mathrm{m}^{2}$ at about $1 \mathrm{pm}$;

iv. the night-time luminance yields its peak when the sample is removed from solar radiation (at about $4 \mathrm{pm}$ );

v. $\mathrm{L}_{\mathrm{n}}$ peak is approximately $10^{-5}$ times $\mathrm{L}_{\mathrm{d}}$ peak.

\subsection{Results}

Table 6 illustrates the main results in terms of luminance time and average luminance regarding OGFCs (left) and DGFCs (right).

Note that $t_{1}$ is the time (in seconds) at which luminance measurement starts. In contrast, $\mathrm{t}_{2}$ represents the conventional end of luminance effectiveness $\left(\mathrm{L}<0.01 \mathrm{~cd} / \mathrm{m}^{2}\right.$, Rea et al., 2004; Bullough et al., 2014; Deng et al., 2001).

Table 7 illustrates the average characteristics of samples, in terms of effective porosity $\left(\mathrm{n}_{\text {eff }}\right)$, skid resistance (PTV) and mix bulk specific gravity $\left(\mathrm{G}_{\mathrm{mb}}\right)$.

Table 7. Samples characteristics.

\begin{tabular}{llllllllll}
\hline & \multicolumn{3}{l}{ Before Painting } & \multicolumn{3}{c}{ After Painting } & \multicolumn{3}{c}{ Specification limits $(* *)$} \\
\cline { 2 - 9 } Sample & $\mathrm{G}_{\mathrm{mb}}$ & $\mathrm{n}_{\mathrm{eff}}$ & $\mathrm{AV}_{\mathrm{e}}(*)$ & $\mathrm{PTV}$ & $\mathrm{n}_{\mathrm{eff}}$ & $\mathrm{AV}_{\mathrm{e}}(*)$ & $\mathrm{PTV}$ & $\mathrm{AV}$ & PTV \\
\hline OGFC & 1.86 & 26.6 & 27.3 & 54 & 23.6 & 24.3 & 25 & $16 \div 27$ & $>55$ \\
DGFC & 2.26 & 8.5 & 8.9 & 60 & 8.1 & 8.5 & 13 & $3 \div 8$ & $>60$ \\
\hline
\end{tabular}

Symbols. $n_{\text {eff }}$ : Effective porosity; PTV: Pendulum Test Value; $\mathrm{G}_{\mathrm{mb}}$ : Mix bulk Specific Gravity; DGFC: Dense Graded Friction Course; OGFC: Open Graded Friction Course. $\mathrm{AV}_{\mathrm{e}}$ : estimated air voids content (* Praticò and Moro, 2007); (** ANAS, 2010). 


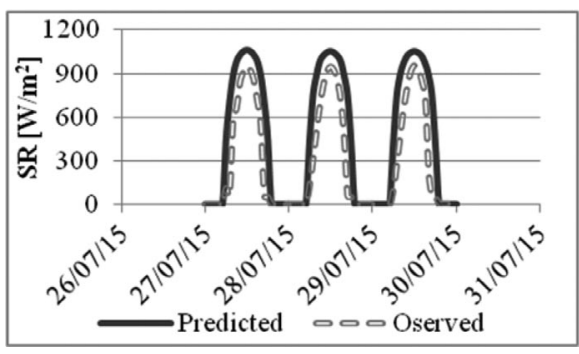

Figure 2. Solar radiation: predicted vs observed.

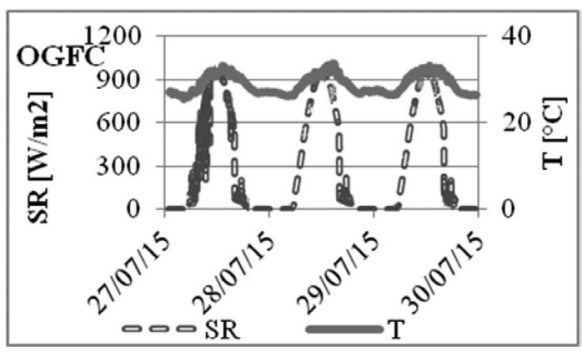

Figure 3. Observed solar radiation and temperature.

Symbols. SR: Solar Radiation $\left[\mathrm{W} / \mathrm{m}^{2}\right]$, T: Temperature $\left[{ }^{\circ} \mathrm{C}\right]$.

Note. Predicted solar radiation was derived based on pveducation.org. Observed solar radiation was measured through the device Vaisala Maws 201.

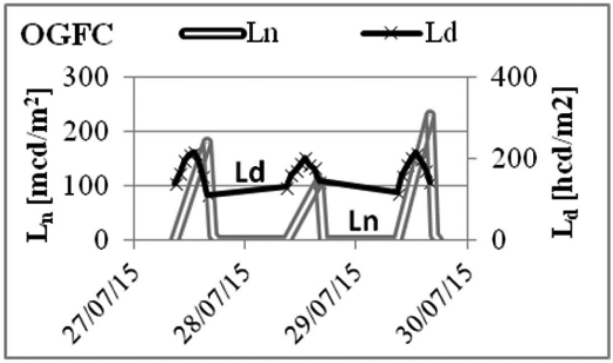

Figure 4. Night-time Luminance $\left(\mathrm{L}_{\mathrm{n}}\right)$ and Luminance during sun time $\left(\mathrm{L}_{\mathrm{d}}\right)$.

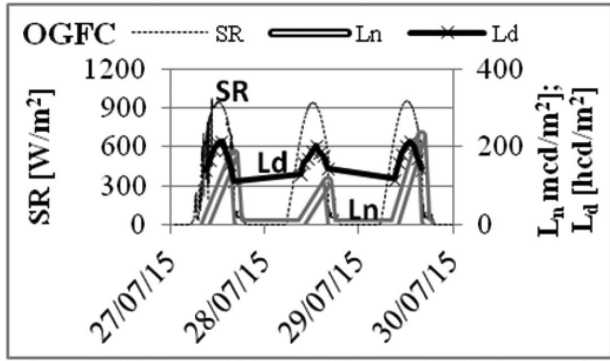

Figure 5. Solar Radiation, Luminance during sun time $\left(\mathrm{L}_{\mathrm{d}}\right)$. Night-time Luminance $\left(\mathrm{L}_{\mathrm{n}}\right)$.

Symbols. SR: Solar Radiation $\left[\mathrm{W} / \mathrm{m}^{2}\right]$, T: Temperature $\left[{ }^{\circ} \mathrm{C}\right] ; \mathrm{L}$ : Luminance $\left[\mathrm{mcd} / \mathrm{m}^{2}\right]$.

Importantly, a decrease of average air voids content (AV) and skid resistance (PTV) can be observed.

Furthermore, it is noted that volumetrics, surface properties, and drainability may be affected by chemical properties of PP. Indeed, the latter is made up of two components, namely photoluminescent paint and catalyser, which is probably responsible for minor phenomena of solution of asphalt binder, which interacts with paint draindown (see Figure 6).

Figures 7 to 10 show how highest luminance $\left(\mathrm{L}_{\max }, \mathrm{cd} / \mathrm{m}^{2}\right)$, luminance time $\left(\mathrm{t}_{\mathrm{L}}, \mathrm{s}\right)$, discharge slope $\left(\mathrm{DS}, \mathrm{cd} / \mathrm{s} \cdot \mathrm{m}^{2}\right)$, and average luminance $\left(\mathrm{L}_{\mathrm{M}}, \mathrm{cd} / \mathrm{m}^{2}\right)$ vary as a function of cycle and Hot Mix Asphalt (HMA) type.

Overall, the following observations can be stated:

- Solar radiation (SR) affects photoluminescent effect (Figures 4 and 5). The higher SR, the higher the effects result.

- Open-graded friction courses, due to their high porosity, have a maximum luminance which is lower than the one exhibited by dense-graded friction courses (the remaining factors being constant, see Figure 7). This disequality applies to all cycles.

- OGFCs exhibit also a luminance time $\left(t_{\mathrm{L}}\right)$ which is lower than the one recorded for DGFCs (see Figure 8). The higher the cycle number is, the lower this difference results.

- Based on the above facts, it turns out that the average luminance during the period of effectiveness $\left(\mathrm{L}>0.01 \mathrm{~cd} / \mathrm{m}^{2}\right)$ is different when comparing OGFCs and DGFCs.

- Cycles affect photoluminescent effect and discharge slopes (see Figure 9). A quite evident tendency towards lower values can be observed.

- Cycles do not affect the maximum luminance according to a clear tendency. The first cycle and successive cycles yield a behaviour which does not call for a decay tendency. 

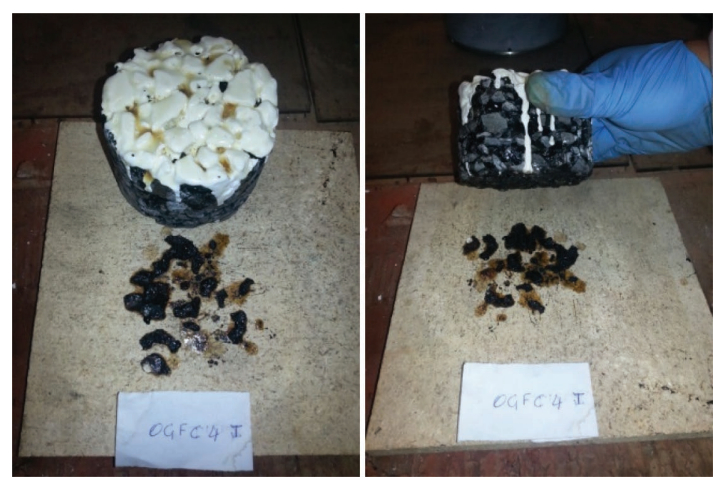

Figure 6. PP draindown and PP-bitumen interaction (bottom of cores). Symbols. PP: Phosphorescent paint.

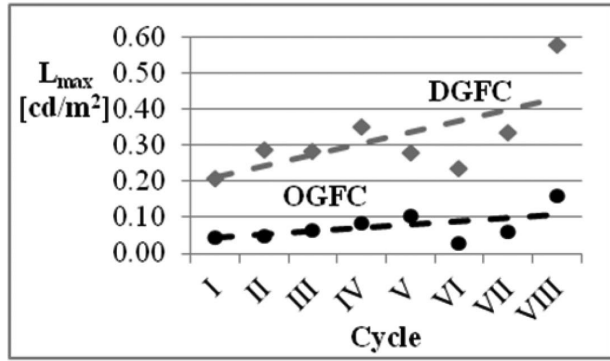

Figure 7. Maximum luminance.

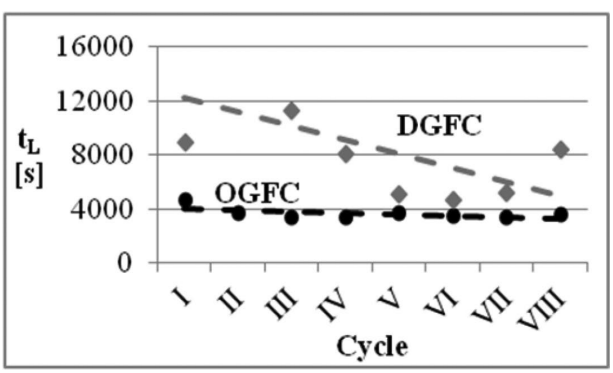

Figure 8. Luminance time.

Symbols. DGFC: Dense Graded Friction Course; OGFC: Open Graded Friction Course; $\mathrm{L}_{\max }$ : Maximum luminance $\left[\mathrm{cd} / \mathrm{m}^{2}\right] ; \mathrm{t}_{\mathrm{L}}$ : Luminance time $[\mathrm{s}]$.

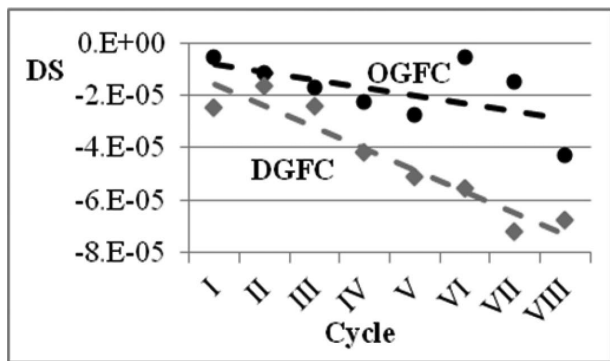

Figure 9. Discharge slope.

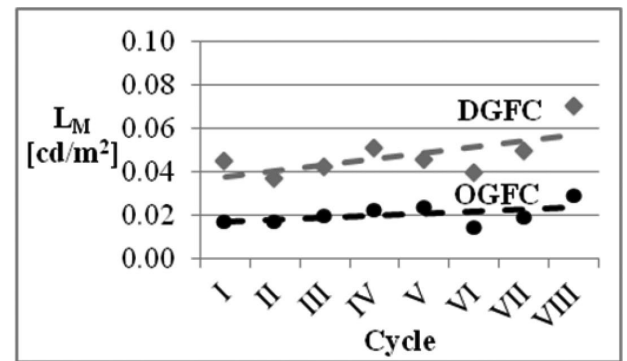

Figure 10. Average luminance.

Symbols. DGFC: Dense Graded Friction Course; OGFC: Open Graded Friction Course; DS: Discharge slope $\left[\mathrm{cd} / \mathrm{s} \cdot \mathrm{m}^{2}\right] ; \mathrm{L}_{\mathrm{M}}$ : Average luminance $\left[\mathrm{cd} / \mathrm{m}^{2}\right]$.

- Further research is needed for luminance time, average value and performance indicators whose variations over time do not show an evident pattern. Importantly, a better knowledge of photoluminescent performance over pavement life cycle and its durability (see Praticò et al., 2010) is vital in terms of life cycle cost analysis and sustainability (Praticò and Vaiana, 2012; Celauro et al, 2015). 


\section{CONCLUSIONS}

Based on data gathered and analyses performed, the following conclusions can be drawn:

1. Measurements point out that there is a relationship between luminance and air void content since this latter influences the effect of the paint on the surface. The paint laid on the surface gradually pours inside the core voids until it reaches the bottom of it (draindown effect). Consequently, there is a limit of paint that can be placed on the top, after which it is not useful going ahead.

2. Samples, either open-graded or dense-graded friction courses, show a quite similar discharge slope for all cycles.

3. Overall, DGFCs perform better than OGFCs.

\section{REFERENCES}

ANAS S.p.A. 2010. CAPITOLATO SPECIALE DI APPALTO - Parte $2^{\circ}$ Norme Tecniche Pavimentazioni stradali/autostradali.

Andrady, A.L. 1997. Pavement Marking Materials: Assessing Environment-Friendly Performance, NCHRP Report 392, Washington, D.C., Transportation Research Board.

Andre, J., Owens D.A. 2001. The twilight envelope: A user-centered approach to describing roadway illumination at night. Human Factors, 43(4): 620-630.

Bacero, R., To, D., Arista, J.P., Dela Cruz, M.K., Villaneva, J.P., Uy, F.A. 2015. Evaluation of Strontium Aluminate in Traffic Paint Pavement Markings for Rural and Unilluminated Roads, 11th International Conference of Eastern Asia Society fir Transportation Studies, EASTS 2015, September 11-14, 2015, Cebu, Philippines.

Bahar, G., Masliah, M., Erwin, T., Tan, E. and Hauer, E. 2006. Pavement Marking Materials and Markers: Real-World Relationship Between Retroreflectivity and Safety Over Time, NCHRP Web Only Document 92, Transportation Research Board.

Barletta, M., Rubino, R., Tagliaferri, V., Vescoa, S. 2014. Design and manufacture of photoluminescent coatings on stainless steel substrates, Colloids and Surfaces A: Physicochemical and Engineering Aspects, 455: 147-155.

Bosurgi, G., D'Andrea, A., Pellegrino, O. 2015. Prediction of Drivers' Visual Strategy Using an Analytical Model, Journal of Transportation Safety and Security, 7(2).

Botterman, J., Smet, P.F. 2015. Persistent phosphor SrA12O4:Eu, Dy in outdoor conditions: saved by the trap distribution, Optics Express, 23(15): 868-881.

Bullough, J.D., Skinner, N.P., Snyder, J.D., Besenecker, U.C. 2014. Nighttime Highway Construction Illumination, SPR Research Study No. C-08-14, Final Report.

Celauro, C., Corriere, F., Guerrieri, M., Lo Casto, B. 2105. Environmentally appraising different pavement and construction scenarios: A comparative analysis for a typical local road, Transportation Research Part D: Transport and Environment, 34: 41-51.

De Beer, M., Maina, J.W., Van Rensburg, Y., Greben, J.M. 2012. Toward using tire-road contact stresses in pavement design and analysis, Tire Science and Technology, 40(4): 246-271.

DIN - German standard. 2009. 67510, Photoluminescent pigments and products - Part 1-4.

Deng, L., Chen, L., Rea, M.S. 2005. An evaluation of the Hunt 94 color appearance model under different light sources at low photopic to low mesopic light levels, Color Research and Application, 30(2): $107-117$.

Gallagher, D., Cyrus, H., and Bassey, R. 2009. Photoluminescent Material Evaluation, Report n. DOT/ FAA/AR-TN09/35, U.S. Department of Transportation Federal Aviation Administration.

Gates, J.T., Hawkins G.H, and Rose, E.R. 2003. Effective Pavement Marking Materials and Applications for Portland Cement Concrete Roadways2, FHWA/TX-03/4150-2, Texas Transportation Institute.

Giuliani, F., Autelitano, F. 2014. Photoluminescent road surface dressing: A first laboratory experimental investigation, Materiaux et Techniques, 102(6-7).

Jiang, Y. 2008. Durability And Retro-Reflectivity Of Pavement Markings (Synthesis Study), Joint Transportation Research Program, FHWA/In/Jtrp-2007/11.

Migletz, J. and Graham, J. 2002. Long-Term Pavement Marking Practices. A Synthesis of Highway Practice, NCHRP Synthesis 306, Washington, D.C., Transport Research Board of the National Academies. 
Mishra, S.B., Mishra, A.K, Revaprasadu, N., Hillie, K.T., Steyn, W.J. vdM., Coetsee, E., Swart, H.C., 2009. Strontium Aluminate/Polymer Composites: Morphology, Luminescent Properties, and Durability, Journal of Applied Polymer Science, 112: 3347-3354.

NYC Department of Building. 2007. MEA 387-07-M, Report of Materials and Equipment Acceptance Division.

Paints Directive 2004/42/EC.

Praticò, F.G., Moro, A. 2007. Permeability and Volumetrics of Porous Asphalt Concrete - A Theoretical and Experimental Investigation, International Journal of Road Materials and Pavement Design, 8: 799-817.

Praticò, F.G., Moro, A., and Ammendola, R. 2010. Potential of fire extinguisher powder as a filler in bituminous mixes", J. Hazard. Mater., 173(1-3), 605-613.

Praticò, F.G., Vaiana, R. 2102. Improving infrastructure sustainability in suburban and urban areas: Is porous asphalt the right answer? And how?, WIT Transactions on the Built Environment, 128: 673-684.

Praticò, F.G., Vaiana, R. 2013. A study on volumetric versus surface properties of wearing courses, Construction and Building Materials, 38: 766-775.

Rea, M.S., Bullough, J.D., Freyssinier, J.P., Bierman, A. 2004. A proposed unified system of photometry. Lighting Research and Technology, 36(2): 85-111.

Specification sheet Epoxy 9000 Paint.

Turnpenny, K., and Crawford, E. 2014. Investigating the potential for reactive 'glowing' roads as an initiative on the Scottish road network, Final Report, Scottish Road Research Board.

UNI EN. 2005. 13036-4, Road and airfield surface characteristics - Test methods: Method for measurement of slip/skid resistance of a surface - The pendulum test. 